\title{
ESPECIALIZACIÓN REGIONAL DE LA PRODUCCIÓN Y EL COMERCIO INDUSTRIAL EN COLOMBIA*
}

\author{
Recibido: 06 de agosto de 2016 - Aprobado: 10 de octubre de 2016 \\ DOI: $10.22395 /$ seec.v19n41a4
}

Edisson Stiven Castro Escobar ${ }^{* *}$

\section{RESUMEN}

El documento revisa las características de la especialización y los flujos de comercio de la producción industrial colombiana, para reconocer sectores clave en la diversificación de las relaciones comerciales en el ámbito regional. Se estimaron dos indicadores a partir del índice de GINI que muestran el grado de especialización y concentración industrial. Igualmente, se analizaron los flujos de productos manufacturados movilizados por carretera, y se contrastaron con el grado de especialización de la producción. Se encontró que el comercio industrial está relacionado con la diversificación de la base productiva, acompañada de varios sub-sectores especializados en cada rama. Este hecho es consistente con la teoría de diferenciación del producto que explica la formación del comercio entre regiones altamente especializadas, incluso en productos homogéneos.

\section{PALABRAS CLAVE}

Comercio interregional, especialización productiva, economía regional.

\section{CLASIFICACIÓN JEL}

F11, R12, R19

\section{CONTENIDO}

Introducción; 1. Especialización productiva y formación del comercio; 2. Algunos antecedentes y evidencias empíricas. 3. Metodología; 4. Estructura del comercio interno y la producción industrial en Colombia, 5. Conclusiones; 6. Bibligrafía. Anexos.

Este artículo de investigación se deriva del proyecto denominado "Diversificación y Fortalecimiento del Comercio de Caldas" desarrollado en el Marco del Programa Jóvenes Innovadores durante el año 2010, asesorado por Irma Soto Vallejo. El proyecto está adscrito al grupo de Economía Internacional clasificado en A2, el cual hace parte de la Facultad de Ciencias Contables Económicas y Administrativas de la Universidad de Manizales.

** Economista, Universidad de Manizales, Manizales, Colombia. Magíster en Economía, Universidad de Manizales, Manizales, Colombia. Estudiante del doctorado en Estudios Territoriales, Universidad de Caldas, Manizales, Colombia. Docente e Investigador del Centro de investigaciones en Medio Ambiente y Desarrollo (CIMAD), Universidad de Manizales, Manizales, Colombia. Dirección: Cra. 8 \# 19-03. Correo electrónico: ecastro@umanizales.edu.co. 


\section{REGIONAL SPECIALIZATION IN INTERNATIONAL TRADE AND PRODUCTION IN COLOMBIA}

\section{ABSTRACT}

This document reviews the specialization characteristics and trade flows for the Colombian industrial production, with the goal of recognizing key sectors in the commercial relations diversification at a regional level. To indicators where estimated using the GINI index, which shows the degree of specialization and industrial concentration. At the same time, the flows of manufactured products transported by land where analyzed and contrasted with the production specialization degree. It was found that industrial trade is related with the productive base, supported by several specialized subsectors within each branch. This fact is consistent with the product differentiation theory, which explains the formation of trade between highly specialized regions, even within homogeneous products.

\section{KEY WORDS}

Interregional trade, Productive specialization, Regional economy.

\section{JEL CLASSIFICATION}

F11, R12, R19

\section{CONTENT}

Introduction; 1. Trade relations and productive specialization; 2. Background and empiric evidence. 3. Methodology; 4. Internal trade structure and the Colombian industrial production, 5. Conclusions; 6. Bibliography. Attachments.

\section{ESPECIALIZAÇÃo REGIONAL DA PRODUÇÃo 0 COMÉRCIO INDUSTRIAL NA COLÔMBIA}

RESUMO

O documento revisa as características da especialização e os fluxos de comércio da produção industrial colombiana, para reconhecer setores chave na diversificação das relações comerciais no âmbito regional. Se estimaram dois indicadores a partir do índice de GINI que mostram o grau de especialização e concentração industrial. Igualmente, se analisaram os fluxos de produtos manufaturados mobilizados por estradas e se contrastaram com o grau de especialização da produção. Se encontrou que o comércio industrial está relacionado com a diversificação da base produtiva, acompanhada de vários subsetores especializados ao interior de cada rama. Este fato é consistente com a teoria de diferenciação do produto que explica a formação do comércio entre regiões altamente especializadas, inclusive em produtos homogéneos.

\section{PALAVRAS CHAVE}

Comércio interregional, especialização produtiva, economia regional.

\section{CLASSIFICAÇÃO JEL}

F11, R12, R19

\section{CONTEÚDO}

Introdução; 1. Relações do comércio e a especialização produtiva; 2. Alguns antecedentes e evidências empíricas. 3. Metodologia; 4. Estrutura do comércio interno e a produção industrial na Colômbia, 5. Conclusões; 6. Bibliografia. Anexos. 


\section{INTRODUCCIÓN}

En un mundo globalizado donde se superponen lógicas progresistas de crecimiento productivo, competitividad, eficiencia técnica y un nivel de integración económica sin precedentes, la política comercial territorial ha tenido marcada una ruta estratégica hacia el crecimiento de las exportaciones en el mercado mundial. De este modo, las agendas territoriales de los departamentos colombianos pretenden aumentar su participación en los mercados externos, basados fundamentalmente en una lectura de la demanda de productos minerales, productos extractivos y bienes básicos, con poco nivel de tecnificación, valor agregado y, sobre todo, vulnerables a perturbaciones coyunturales de los precios mundiales. Bajo este panorama, se han obviado ciertos problemas estructurales como la falta de concertación regional en la división del trabajo y la construcción de encadenamientos para producción a escala, la fragilidad competitiva, especialmente de productos con intensidad tecnológica, los costos de transporte interno y, sobre todo, bajos niveles de especialización industrial que tienden a ser monosectoriales y con una base de diversificación muy restringida.

Aunque en Colombia, según Jaramillo y Parra (2012), la apertura económica no alteró significativamente la localización de la industria, si tuvo un impacto importante sobre todo en regiones periféricas que sufrieron cierta reconversión y desaceleración del crecimiento industrial, con lo cual muchas firmas se dedicaron a la proveeduría local, a la reorganización productiva, la relocalización espacial, o simplemente, salieron del mercado. Por esta razón en este trabajo se revisan algunas condiciones internas que puedan dinamizar la integración regional del comercio y la producción industrial como una estrategia para fortalecer el mercado y la producción local. Aunque no se trata de volver a un modelo de sustitución de importaciones, es necesario reconocer la ventaja que representa la demanda local, especialmente para las regiones de menor tamaño y con un grado de industria especializada que, como lo plantea la teoría y se valida en este trabajo, tiene un potencial importante de integración comercial.

El esfuerzo se concentra en identificar características de los principales protagonistas del comercio interno en Colombia y los sectores industriales que pueden ser claves en la diversificación de las relaciones comerciales en el ámbito interregional. Posteriormente se hace una revisión de las condiciones de especialización productiva en la industria colombiana, mediante la construcción de un índice que mide la concentración del valor agregado, la producción y el empleo a partir de datos de la encuesta anual manufacturera del Departamento Administrativo Nacional de Estadística (DANE). Posteriormente esos resultados se relacionaron con los flujos de carga terrestre movilizada por carretera, captados a través de una muestra tomada por el Ministerio de Transporte. 
Algunos resultados del ejercicio dan cuenta de una alta concentración de la producción en el centro del país, la cual, a su vez, explica los sentidos y magnitudes del comercio interno. Para algunos sectores productivos se registró una relación significativa entre la especialización industrial y el comercio; no obstante, hay otros altamente especializados que no registran fuertes movimientos de carga o, por el contrario, son sectores que, pese a su bajo nivel de especialidad, reportan volúmenes de carga muy dinámicos. Estas diferencias se le atribuyen a la naturaleza transable de los bienes y a las características de la demanda interna en el país.

En la primera sección del artículo, se abordan algunas discusiones teóricas que han explicado la formación del comercio, la especialización productiva y la integración regional. Luego se muestran algunos antecedentes y evidencias empíricas sobre la concentración regional y sectorial de la producción y la manera como se cree que influyen en las relaciones bilaterales del comercio. Seguidamente, se presenta el abordaje metodológico con los indicadores y la información empleada en este trabajo. Más adelante se hace una revisión de los flujos comerciales en el interior del país, las tendencias de especialización productiva y ciertos elementos de localización y concentración de la producción que aparentemente determinan los patrones comerciales regionales. Finalmente, se muestran las conclusiones y discusiones más importantes del estudio.

\section{ESPECIALIZACIÓN PRODUCTIVA Y FORMACIÓN DEL COMERCIO}

Teóricamente ha existido una relación importante entre la especialización de la producción y la formación del comercio, de manera que las regiones que tienen mejores condiciones de desarrollo y concentración de la actividad económica son, según Krugman (1980), las más dinámicas en la transacción de mercancías. Esta idea ha sido transversal a lo lardo del tiempo, de acuerdo con Emaldi (1991), y se ha nutrido de un vasto conjunto de proposiciones en torno a la ventajas competitivas, producto de la especialización y la dotación factorial, las distancias geográficas, el tamaño de los mercados y la disponibilidad de recursos naturales. Asimismo, por el lado de la demanda se han asumido nuevas consideraciones más complejas sobre las preferencias de los consumidores en función de la calidad, la variedad y los precios de los productos. De esta forma, siguiendo la propuesta de Bajo (1991), es posible clasificar las teorías que exponen la formación del comercio en dos vías: unas, asociadas a las condiciones de oferta, como un resultado de las distintas dotaciones factoriales regionales y sectoriales, en el marco de la competencia perfecta, y otras, sustentadas en características de la demanda y las fuerzas geográficas de organización del mercado, en las cuales este se desarrolla en condiciones de competencia imperfecta. 
En las teorías clásica y neoclásica del comerciol los flujos de mercancías entre regiones son producto de un stock residual de la oferta, donde la presencia de ventajas absolutas y ventajas comparativas da lugar a la especialización relativa de la producción y la división del trabajo, lo que permite generar excedentes para comerciar los bienes en los que se ha especializado en términos de costo-eficiencia. Este enfoque, descrito por Appleyard y Field (2003), produce precios de mercado más competitivos, con lo cual las ganancias se sustentan en la ventaja comparativa y no en la absoluta, lo que aumenta la eficiencia en el uso de los recursos y el bienestar, y en teoría da lugar a la división regional de la producción. No obstante, Emaldi (1991) indica que la desventaja de este conjunto de proposiciones es la restricción para explicar la formación del comercio, entre regiones, con especialización productiva en productos similares que difieren en calidad y otras características que se captan por el lado de la demanda.

Asimismo, tienen restricciones porque asumen la ausencia de costos de transporte y simetría en las funciones de producción y en las preferencias de los consumidores. Appleyard y Field (2003) mencionan que el modelo, además, es muy restrictivo sobre las condiciones de movilidad factorial y las barreras comerciales que pueden interrumpir las tendencias de los precios y la producción². Según Berumen (2006) los contrastes empíricos de la teoría neoclásica no han sido muy consistentes, ya que se ha demostrado que algunas regiones especializadas en la producción de bienes intensivos en un factor relativamente abundante tienen ciertos niveles de importación de ese mismo bien, lo cual sería inconciliable con las propuestas fundamentales del modelo teórico.

De este modo, en el segundo grupo de teorías se discute la diferencia en la implementación de la tecnología y la innovación, la presencia de economías de escala y la integración comercial de productos diferenciados como determinantes del comercio y la especialización de la producción. Algunos de los principales argumentos exponen que el comercio intra-industrial se da en mercados de productos cuya estructura es imperfecta debido a las diferencias en las preferencias de los consumidores, los rendimientos crecientes a escala y la segmentación de los mercados (teoría del comercio intra-industrial). Asimismo, se reconoce que la incorporación regional de la tecnología y la innovación tiene rezagos, lo que permite explicar el comercio según el desfase tecnológico y el ciclo de vida de los productos (este el principal argumento de las teorías neotecnológicas). El resultado de estas interacciones temporales sugiere una dinámica cambiante en la localización espacial

Introducidas por Adam Smith, David Ricardo, Eli Hecksher y Bertil Ohlin.

2 A esto se suman todas las restricciones que impone de entrada la consideración que mercado se desarrollan en términos de competencia perfecta. 
de la producción y el comercio a medida que surgen nuevas innovaciones o que los productos tienden a estandarizarse en regiones menos desarrolladas.

Seguidamente, en este grupo de teorías se introduce, por primera vez, la influencia de la organización industrial sobre las relaciones del comercio y la especialización de la producción, según la importancia de los mercados internos (demanda), la estructura productiva y la eficiencia técnica. En esta línea, White (1974) pone énfasis en la importancia de la diferenciación del producto y la fuerte relación con el comercio, especialmente el que se da entre las industrias intermedias. Según Dixit y Stiglizt (1977), la teoría de la diferenciación del producto es un resultado de intentar que los modelos neoclásicos sean más efectivos, sin considerar especialmente el supuesto sobre la simetría en las preferencias de los consumidores. En este caso se plantea que estos desearían consumir el mayor número de variedades de un bien diferenciado por atributos y características particulares, lo que daría mayor dinamismo a los flujos de mercancías ${ }^{3}$. Esta es una línea fundamental para explicar el enfoque teórico del presente trabajo, de modo que ofrece explicaciones contundentes para distinguir los factores que determinan la integración comercial de industrias homogéneas y altamente especializadas. Además se complementa fácilmente con principios de localización de las actividades económicas, el nivel de demanda, los costos de transporte y otras particularidades que explican la concentración geográfica de la producción y el comercio bajo el enfoque contemporáneo de la nueva geografía económica presentado por Krugman, (1980). En la línea de lo anterior, la localización y las interacciones espaciales cobran fuerza a la hora de resolver problemas que la teoría convencional no logró superar, porque tienen la ventaja de que expresan el comercio a partir de lo que sucede en el interior de las regiones. La tabla 1 ofrece una mirada general del desarrollo teórico que se ha dado alrededor de las relaciones comerciales y las dinámicas de especialización productiva.

En la actualidad, las explicaciones sobre la formación del comercio se han desarrollado sobre aspectos de la localización espacial de la producción y los costos de transporte y acceso a los mercados como determinantes de la concentración productiva. Como se ha explicado desde los principios de la NGE, introducidos por Krugman (1998), la concentración de la producción y la especialización de la industria se producen por una serie de factores que se mueven como fuerzas opuestas; por un lado, el aumento del tamaño de los mercados y los encadenamientos, la concentración del trabajo y el crecimiento de actividades espurias, producto de la movilidad de capital, han sido dominantes como fuerzas de concentración o también conocidas como fuerzas centrípetas, mientras las fuerzas de dispersión o centrífugas se

La diferenciación del producto, se puede dar de manera horizontal en la que hay igualdad de condiciones de calidad y de manera vertical, donde la calidad es diferente. 
relacionan, sobre todo, con la fijación de los factores productivos, la renta del suelo y las deseconomías de escala.

Tabla 1. Teorías que explican la especialización productiva y el comercio regional

\begin{tabular}{|c|c|c|c|}
\hline \multicolumn{2}{|c|}{ Clásicas y Neoclásicas } & \multicolumn{2}{|c|}{ Contemporáneas } \\
\hline $\begin{array}{l}\text { Teorías Clásicas: } \\
\text { - Ventajas Absolutas } \\
\text { - Ventajas Comparati- } \\
\text { vas }\end{array}$ & $\begin{array}{l}\text { Teorías Neofactoriales: } \\
\text { - Hecksher-Ohlin } \\
\text { - Rybczynski } \\
\text { - Stolper-Samuleson }\end{array}$ & $\begin{array}{l}\text { Teoría del comercio } \\
\text { Intraindustrial } \\
\text { Teorías Neotecnoló- } \\
\text { gicas: } \\
\text { - Desfase tecnológico } \\
\text { - Ciclo de vida del pro- } \\
\text { ducto } \\
\text { - Diferenciación del } \\
\text { producto } \\
\text { - Economías de escala }\end{array}$ & $\begin{array}{l}\text { Innovación, tecnología } \\
\text { y crecimiento } \\
\text { Nueva Geografía Eco- } \\
\text { nómica (NGE): } \\
\text { - Localización } \\
\text { - Aglomeración y Con- } \\
\text { centración } \\
\text { - Costos de transporte }\end{array}$ \\
\hline \multicolumn{2}{|c|}{ Competencia perfecta } & \multicolumn{2}{|c|}{ Competencia imperfecta } \\
\hline
\end{tabular}

Fuente: Elaboración propia

En este caso, la localización de las firmas se determina por el tamaño de los mercados y los incentivos de aglomerarse en distritos industriales, donde se facilita el acceso y la disminución de los costos de transporte, aprovechando al tiempo los beneficios de las economías de escala. A diferencia de lo que plantean las teorías convencionales de competencia perfecta, el espacio geográfico no es homogéneo; por tanto, los costos de transportes son una variable clave. Como lo plantea Krugman (1980, p. 954):

In a world characterized both by increasing returns and by transportation costs, there will obviously be an incentive to concentrate production of a good near its largest market, even if there is some demand for the good elsewhere. The reason is simply that by concentrating production in one place, one can realize the scale economies, while by locating near the larger market, one minimizes transportation costs.

Según Krugman (1991), la especialización y concentración económica obedece, en primera instancia, a hechos fortuitos que se explican mejor por la historia que por vía determinística. Asimismo, las expectativas son importantes como motor de concentración en la medida que provocan desplazamiento de población (agentes de demanda) y modifican el patrón de incentivos a la localización de la industria por cuenta de los cambios en la demanda. Mientras por el lado de la oferta, dice Krugman (1992), la concentración y conformación de distritos industriales se va formando en función de mejorar las ventajas de mercado, el aprovisionamiento y la respuesta a los impulsos tecnológicos 
Es precisamente en los lugares de mayor concentración económica donde el comercio tiene más dinámica. De acuerdo con Krugman (1980) los volúmenes de producción en escala y las ganancias que se obtienen del comercio vienen determinadas únicamente a través de una mayor diversidad de productos (lo que es consistente con las propuestas de Dixit y Stiglizt (1977) sobre la asimetría de las preferencia de los consumidores); por lo tanto, los países tienden a exportar productos en la medida que tienen grandes mercados internos, porque la extensión en el volumen de producción a escala les permite tener excedentes y ser más competitivos en precios. En otras palabras, la heterogeneidad de las empresas determina en parte el tamaño del mercado, de manera que los mercados más grandes posibilitan una mayor variedad de subsectores y mejores condiciones de competitividad en precios. Como lo dicen Melitz y Ottaviano (2008, p. 296), "the bigger market still exhibits larger and more productive firms as well as more product variety, lower prices, and lower mark-ups".

La cuestión es que el comercio, según Melitz (2003), obliga a las empresas a reorganizarse, de tal modo que las menos productivas tienden a salir del mercado o a volverse proveedoras únicamente en el mercado local, ya que el comercio costoso no se integra completamente a los mercados globales, mientras las firmas más grandes se integran con más facilidad mejorando su competitividad en precios. Esto hace que tienda a haber relocalización empresarial y, en conjunto, aumente la competitividad del mercado que induce a cambios agregados en el bienestar del país. Por lo tanto, las políticas de liberalización comercial inciden en la lógica de organización de esas industrias en el mercado, sea sectorial o regionalmente. No obstante, este sistema, desde la perspectiva de Krugman (1991), puede generar una marcada concentración de la producción industrial y desarrollarse en un modelo centro-periferia, determinado por los costos de transporte y las economías de escala.

En síntesis, la explicación de los patrones comerciales se ha planteado teóricamente desde varios enfoques. En la literatura clásica, es un hecho determinado por la concentración de la producción y los excedentes de la misma, de tal forma que las regiones buscan comerciar los bienes en los que potencialmente tienen más destreza productiva. Asimismo, la dotación factorial inicial y las ventajas de la concentración del capital y el trabajo tienden a determinar las áreas con mayor productividad y rendimientos que favorecen la actividad exportadora. Bajo este enfoque, la base del comercio sería solo una cuestión de las condiciones de oferta de las regiones. Sin embargo, la teoría contemporánea contempla los efectos de la demanda interna, al reconocer que el tamaño de los mercados y las diferencias en las preferencias de los consumidores son fundamentales para determinar los patrones de producción y comercio. En ese sentido, las regiones con mercados más grandes tendrían una dinámica comercial más fuerte con otras regiones muy especializadas. 
A esto se suma que las menores distancias relativas a los puntos de aglomeración se convierten en una ventaja comparativa que favorece la integración regional por el aprovechamiento de externalidades y los efectos espaciales que potencian el crecimiento. Es así que los mercados más concentrados y geográficamente más cercanos favorecen la integración comercial y la producción encadenada entre las regiones aledañas; además, las condiciones de diversificación de la base productiva y la especialización industrial, intensifican ese proceso.

\section{ALGUNOS ANTECEDENTES Y EVIDENCIAS EMPÍRICAS}

Los referentes de análisis sobre las relaciones entre especialización de la producción manufacturera y las dinámicas de integración comercial entre regiones se han considerado en dos vías: la una desde la dinámica de transformación productiva y las tendencias de concentración regional de la industria, y la otra desde los patrones de comercialización de mercancías intra-industrial. Para esto se analizaron varios trabajos de Europa y algunos del caso colombiano.

En primera instancia, Jaumandreu y Mato (1985) analizaron la concentración regional de la producción en España y los cambios estructurales que dan cuenta de una transformación hacia grandes sectores económicos en el período de 1973 a 1981. Los autores tuvieron en cuenta índices como el Herfindahl-Hirschman (en adelante HH), un índice de entropía e indicadores de tipo Hannah-Kay para analizar el comportamiento de las ventas sectoriales de la industria y el empleo. En el trabajo se identificó un grado de concentración de la industria en el período estudiado que predominó en la manufacturación siderúrgica, el transporte, materiales energéticos y extractivos, mientras que las industrias livianas de los alimentos, textiles, calzado y madera estuvieron poco concentradas. Se prevé que la concentración estuvo determinada por diferenciales en el crecimiento del tamaño del mercado, los gastos publicitarios o en I+D, los costos y la tecnología de producción a escala que incidieron en la eficiencia productiva. En este estudio, al igual que en el de Tipurić y Pejić (2009) con el caso de Croacia, se notan estímulos y efectos en la concentración por cuenta de los impulsos políticos inducidos como la privatización, la presencia de compañías multinacionales y la desregulación. Aunque en sentido estricto no son comparables los hechos de España y Croacia, la intervención pública o privada incidió en los grados de concentración, por lo cual no se podría entender como un hecho meramente estocástico como se plantea en algunos casos.

De manera más concentra en España, Furió y Alonso (2009) estudiaron la concentración de la industria hotelera; esta vez se buscó reconocer el efecto de concentración que tiene este sector en España con relación al mercado europeo. 
Para esto calculó y comparó una cesta amplia de indicadores derivados del GINI, el índice HH, el de Jerarquía y el índice de Rosenbluth. De manera sectorial los autores encuentran que España tiene baja concentración de la industria en términos de especialización sectorial y más bien se percibe un grado importante de heterogeneidad, especialmente en el sector hotelero.

En un caso similar, Bosco (2005) analizó los patrones de especialización y concentración de las actividades económicas entre regiones de Italia durante los años de 1995 a 2003. El autor estimó las condiciones de especialización relativa y absoluta a partir del índice $\mathrm{HH}$ y el índice de Krugman; entre tanto, la concentración la midió desde el índice HH y un índice de concentración relativa (ICR). También se llevaron a cabo algunas estimaciones de clústeres regionales de la producción analizados mediante dendogramas. Los resultados del trabajo indican que el país se ha polarizado con fuerza durante el período de análisis, las diferencias han sido más marcadas entre las regiones del norte y el sur de Italia, donde hay una progresiva pérdida del empleo industrial, como resultado de la transformación de la economía mediante la disminución del Estado y las privatizaciones y un efecto colateral muy fuerte del comercio internacional. Según el autor, el país está en un panorama en el que han disminuido las exportaciones por cuenta de la competencia internacional, especialmente en los sectores tradicionales, al tiempo que se percibe un rezago en el ritmo de innovación. Estos hechos se pueden comparar con lo que ha sucedido en Croacia y en España según Tipurić y Pejić (2009) y Jaumandreu y Mato (1985), respectivamente, donde la perturbación de los costos de producción, las transformaciones tecnológicas y el rezago en I+D han tendido un fuerte efecto en la concentración espacial y sectorial de la producción. Asimismo, los estímulos de las políticas de apertura comercial, las privatizaciones del Estado y la desregulación del mercado incidieron en la marcada polarización de Italia.

En un plano más global para la Unión Europea, Gordo, Gil y Pérez (2003) estudiaron las condiciones de especialización industrial en Europa para determinar procesos de integración regional que han afectado la estructura productiva de los países y generado una redistribución geográfica de la industria. Para esto se estimaron indicadores de especialización y concentración de la producción mediante el índice de $\mathrm{HH}$, el índice de Krugman, un índice de Hoover-Balassa y el índice de GINI en términos absolutos y relativos. A diferencia del enfoque de Bosco (2005), en este trabajo se asumió la especialización según la distribución sectorial de la producción y la concentración en la estructuración regional del mercado. De acuerdo con los resultados la estructura productiva de la Unión Europea no experimentó grandes cambios durante los ochenta, excepto algunos países nórdicos que se han especializado en industrias con más valor tecnológico, mientras otros de la región 
central, como Alemania, presentaron cierto patrón de reconversión. De manera general se notó una leve concentración de la industria con mayor potencial tecnológico en la zona norte, mientras en el sur se marcó la concentración de la industria intensiva en trabajo. A diferencia de los postulados de Melitz (2003) en la industria europea, la política de apertura comercial no generó profundas transformaciones en materia de relocalización y mayor concentración de la producción; por lo tanto, no se corroboró la teoría tradicional sobre el efecto del comercio internacional que aumenta las disparidades regionales. Según los autores, es posible que a diferencia de Estados Unidos, en Europa el idioma haya sido factor contendor de la concentración económica.

Rapún et al. (2003) analizaron igualmente la distribución espacial de la actividad económica en las regiones de la Unión Europea entre 1977 y 1999. En concreto se revisó el grado de especialización y concentración desde una mirada de las condiciones de desigualdad y polarización de los ingresos. Para esto emplearon los índices de GINI y el Krugman para mirar la evolución en términos de desequilibrios territoriales; al final se determinaron unos clústeres sectoriales y regionales. Como resultado se nota un progresivo aumento de la especialización productiva, especialmente en sectores industriales, al tiempo que ha menguado la especialización agropecuaria, la cual está más dispersa. Se cree que han incidido en estos hechos las distancias geográficas y las variables de masa y densidad de la demanda, en un proceso de contagio espacial que ha ido formando clústeres.

En el caso colombiano, los trabajos que se han realizado analizan fundamentalmente la estructura productiva de los departamentos, las disparidades regionales y brechas estructurales del crecimiento, la dotación factorial y la geografía económica del país. Bonet (1999), por ejemplo, hizo un seguimiento de la estructura productiva, y encontró que los departamentos con vocación en sectores más rezagados y tradicionales presentan grados de especialización más bajos y con menor incidencia e integración en el contexto en la economía nacional.

Por su parte, Jaramillo y Parra (2012) estudiaron la localización empresarial en Colombia, con miras a reconocer el efecto de relocalización por cuenta de la apertura comercial. Los autores usaron datos de la encuesta anual manufacturera (EAM) para calcular algunos índices de concentración y especialización industrial, derivados de una matriz sectorial y regional. Además, estimaron un índice de especialización (Qr), de concentración espacial (Qs), y una medida de redistribución y reestructuración para mirar las oscilaciones intertemporales. En los resultados se menciona que si bien no hubo cambios estructurales de localización, se notó una mayor concentración de la industria ya especializada en las regiones del país 
donde había consolidadas fuertes estructuras de mercado. Estos resultados tienen patrones similares a lo encontrado por Jaumandreu y Mato (1985) en España. En otras palabras, con la apertura comercial, dicen Jaramillo y Parra (2012, p. 82), no se logró desanclar la concentración regional y sectorial de la industria, "... la estructura productiva no se modificó y el sector industrial, en lugar de fortalecerse, continuó mostrando el mismo declive que en las décadas anteriores"; de este modo, y contrario a lo que se esperaba, las economías periféricas no se involucraron precipitadamente con la estructura productiva del país. Los resultados de concentración se focalizaron en productos alimenticios, textiles, industria del papel, derivados del petróleo, sustancias y productos químicos, entre otros.

No obstante, en regiones periféricas donde hubo enclaves productivos, las condiciones de especialización de la industria fueron diferentes. Por ejemplo, en el caso del Putumayo, Burbano (2005) analizó el fenómeno de extracción productiva y la manera como éste afectó la estructura de la producción debido a factores exógenos como los cambios en las reglas del negocio petrolero y la seguridad interna. El autor estimó algunos índices de localización, especialización y concentración sectorial con los índices de HH, Krugman y Hoover-Balassa; luego con ellos estimó las dinámicas departamentales de convergencia absoluta, condicional y por clubes, tratando de observar la posición del Putumayo frente a otras regiones. En los resultados muestra cómo algunos efectos en la coyuntura de los precios de los commodities, las reservas petroleras y el conflicto armado incidieron de manera importante en la localización de las empresas, aunque esta última variable no definió particularmente la especialización sectorial en la región, de manera contraria a lo que podría esperarse. Además, se menciona cómo la industria petrolera ha jalonado el crecimiento de otros sectores, sobre todo los no transables. Mientras tanto, los sectores primarios se desaceleraron, lo que induce a una indudable reconversión productiva. Los indicadores de especialización indican que el Departamento viene especializándose de manera similar a otros departamentos de la región oriental del país; no obstante, la dependencia de un modelo basado en la actividad extractiva hace más vulnerable la economía local porque tiende a generar concentración productiva en unos pocos sectores.

En material de integración comercial Martín y Orts (1996) estudiaron la relación entre comercio y especialización productiva entre España y la comunidad Europea. A diferencia de los trabajos descritos con anterioridad que se fijan sobre todo en la revisión de condiciones de concentración y especialización de la industria, en este trabajo se tuvo en cuenta el comercio bilateral en dos sentidos: de forma vertical entre industrias intermedias, y de manera horizontal por la diferenciación en la calidad de productos similares. Mediante la estimación de un índice de Grubel y 
Lloyd (GL) se demuestra cómo la industria de alimentos es la que produce mayores ritmos de integración comercial en Europa. Posteriormente, Martin y Orts (2002) evidenciaron cómo predominaban los intercambios de productos de baja calidad (80 \% de los flujos), lo cual está asociado especialmente a diferenciales tecnológicos. Para el mismo caso de España, Álvarez (2005) y Álvarez y Troyano (2006) expusieron mediante el uso del índice de Grubel y Lloyd a nivel de comercio intra-industrial, de qué manera el comercio de manufacturas intermedias ha sido más predominante, mientras que en el comercio inter-industrial, han sido más intensivos los flujos de productos terminados como los alimentos. Nuevamente los resultados de un estudio empírico validan que la industria de alimentos y los minerales son de naturaleza horizontal y más dinámica comercialmente.

En el caso colombiano, por desgracia, se cuenta con poca información sobre integración comercial. Se han hecho algunos acercamientos con métodos indirectos como el caso de Bonet (2005) quien estudió los cambios estructurales del país y el nivel de integración mediante el uso de matrices de insumo-producto; sin embargo, aunque que se puede intuir un nivel bajo de integración y cierta autosuficiencia regional, no hay registros claros desde el punto de vista sectorial que permitan mirar dinámicas más claras sobre ese proceso. Los datos clave para el seguimiento de la integración comercial se han basado en las encuestas de origen y destino de carga terrestre del Ministerio de Transporte. Con este insumo, Pérez (2005) estudió en 2001 el movimiento de carga entre regiones mostrando una dinámica importante entre Cali, Medellín y Bogotá. Según el estudio la mayor parte de productos que se movilizan por carretera entre regiones tienen un valor agregado relativamente bajo. Estos hechos se validaron posteriormente por Castro (2014) quien indica que las industrias más especializadas en Colombia no necesariamente son las que mejor se integran comercialmente con otras regiones, exceptuando la industria de alimentos y productos químicos. En general se advierte que el nivel de integración es moderado, por cuenta de una estructura productiva poco especializada, lo que validaría algunos de los argumentos de Melitz (2003) sobre la exclusión de las regiones poco competitivas del escenario comercial global, en este caso, del mercado interno.

\section{METODOLOGÍA}

Para el análisis de los flujos comerciales internos se utiliza la información de la encuesta de origen-destino de carga terrestre del Ministerio de Transporte para el año 2008. Esto con el fin de observar el número de viajes movilizados por carretera a partir de una matriz de origen y destino que permitiera establecer las áreas de influencia del comercio regional en Colombia. Para el análisis de la producción industrial se analizó información de la EAM del Departamento Nacional de Estadís- 
tica (DANE) para el período 2008-2009. A partir de esta información se elaboró el indicador de concentración y especialización de la producción industrial para los 32 departamentos del país; no obstante, en algunos casos se agregan regionalmente algunos resultados ${ }^{4}$.

En varios trabajos empíricos es muy común el uso de índices absolutos y relativos para conocer la distribución sectorial o geográfica de las actividades económicas de una región. De este modo, a los indicadores de densificación sectorial se les conoce como índices de especialización productiva que muestran los sesgos hacia determinadas industrias dentro de la estructura económica en su conjunto, mientras que la concentración productiva indica la manera como está distribuida la industria en distintas regiones. Esta visión es particular de Gordo, Gil y Pérez (2003) en el estudio que hacen para la Unión Europea. Esto hace referencia a la doble dimensión de los indicadores, en la que según Furio y Alonso (2008, p, 42), se pueden evidenciar las condiciones de "concentración de mercado y de concentración agregada".

Los indicadores más comunes para estas estimaciones se les conoce como los índices de la familia Hannah-Kay, dentro de los cuales predomina el índice de Herfilndalf-Hisrscham (HH); asimismo, están los índices de concentración y de condiciones de entropía. Esas clasificaciones tienden a presentarse en términos absolutos y relativos, con lo cual el primer enfoque se usa para los análisis verticales dentro de una misma unidad, mientras el segundo es más sensible a las comparaciones. Según Jaumandreu y Mato (1987, p. 46) los indicadores "... solo difieren en el sistema de ponderaciones que adoptan para agregar las cuotas individuales de mercado". En la siguiente tabla se presentan los índices más comunes según el tipo de enfoque de medición:

Tabla 2. Índices de concentración y especialización industrial

\begin{tabular}{|l|l|l|}
\hline Enfoque & Concentración & Especialización \\
\hline Absoluto & $\begin{array}{l}\text { Herfilndalf-Hisrscham } \\
\text { GINI }\end{array}$ & $\begin{array}{l}\text { Herfilndalf-Hisrscham } \\
\text { GINI }\end{array}$ \\
\hline Relativo & $\begin{array}{l}\text { Índice de Krugman } \\
\text { Índice de Rosenbluth } \\
\text { Índice de Hoover-Balassa } \\
\text { GINI }\end{array}$ & $\begin{array}{l}\text { Índice de Krugman } \\
\text { Índice de Rosenbluth } \\
\text { Índice de concentración Relativa } \\
\text { GINI }\end{array}$ \\
\hline
\end{tabular}

Fuente: elaboración propia

$4 \quad$ La base de datos usada para este estudio, esta disponible para otras investigaciones mediante solicitud institucional, dando créditos a la Universidad de Manizales por el aporte de la información. Para solicitarla comunicarse al correo: ecastro@umanizales.edu.co. 
Para este trabajo se utilizó el índice de GINI como técnica de medición comparativa según la concentración del empleo y el valor agregado de acuerdo con las ramas de la industria por departamento. El GINI es comúnmente usado para medir el nivel de desigualdad en la distribución de la renta; sin embargo, se puede usar en este caso como medida para identificar la concentración productiva. El límite inferior es cero (0) y el superior uno (1). Como medida de especialización o concentración indica que los valores próximos a 1 estarán más concentrados y los cercanos a 0 más dispersos.

Dónde:

$$
\mathrm{IG}=\frac{1}{2 n^{2}} \frac{1}{\mu} \stackrel{n}{a} \underset{i}{a} \stackrel{n}{a} a_{j=1}^{a}\left|\frac{\mathrm{P}_{i}}{\mathrm{P}_{\text {total }}}-\frac{\mathrm{P}_{i}}{\mathrm{P}_{\text {total }}}\right|
$$

$\mathrm{N}=$ número de ramas

IG = índice de Gini

$\mathrm{P}=$ Producción industrial

I y $j=$ todas las ramas

$\mu=$ cuota media de las ramas

El análisis de especialización productiva a través del índice de GINI sirve para comprender las dinámicas de concentración del empleo, la producción y el valor agregado en una región particular. Sin embargo, se debe tener cuidado cuando se hacen comparaciones regionales de los resultados sin descomponer los pesos frente a otras regiones, de tal manera que estos se estimen en términos relativos, sobre la significancia de esa concentración. En tal sentido, en este documento se desarrolló una propuesta a partir del GINI que incluye los pesos relativos frente a la base industrial del país; a esta propuesta se le denomina índice de especialización relativa. El resultado se obtiene de acuerdo con la base potencial manufacturera que debería tener una región si estuviera completamente diversificada según la base industrial de todo el sistema de mercado. El indicador de especialización relativa toma valores de cero (0) en los $n$ sectores donde no hay producción dentro del departamento . A continuación se expresa la función del índice:

Dónde:

$$
\sum_{k=1}^{m} \widehat{G}_{i} / m
$$

$\hat{G}_{i}$ GINI del departamento $i$ para el sector $n$ 
m Número de ramas que conforman la base industrial del país

n Ramas que conforman la base industrial del departamento $i$

K Unidades regionales o Departamentos

Esta medida también puede ser aplicable para identificar concentración regional de la producción de un sector, al considerar todas las posibles regiones con potencial productivo. La tabla 3 muestra las diferencias en la distribución del índice de GINI como media de especialización absoluta y especialización relativa. Para poder hacer comparaciones, se construyó una escala a partir del valor que toma el indicador de acuerdo con una división por quintiles 5 . El grado de especialización relativa toma como referente la región con el valor más alto al suponer que esta tendría la base industrial más diversificada por sector (CIIU 2D) y en el interior de esta varios sectores especializados (CIIU 3D).

Tabla 3. Lógica de especialización industrial absoluta y relativa

\begin{tabular}{|c|c|}
\hline ESPECIALIZACIÓN ABSOLUTA & ESPECIALIZACIÓN RELATIVA \\
\hline Grado de especialización & Grado de especialización \\
\hline
\end{tabular}

Fuente: elaboración propia

Con la suavización que permite el índice de especialización relativa, es posible tener un panorama más claro de la estructura productiva del país por subramas y subregiones en vista de que este ha sido estimado en función del potencial productivo del país. Este índice, además, cumple con una serie de recomendaciones que sugieren Furio y Alonso (2008) sobre la facilidad de medición e interpretación, la unidimensionalidad y la capacidad para captar la oposición a la dispersión y la uniformidad. A diferencia de otros índices de concentración en sentido estricto que no tienen elementos de comparación al considerar la totalidad como una uniformidad, la propuesta evalúa la concentración en función de la disfuncionalidad de la uniformidad, teniendo en cuenta que las unidades de medición tienen como punto de partida, expresiones diferentes que se pueden revisar en el marco de un núcleo básico de estandarización.

Las categorías asignadas a los rangos son: Muy Alto (0,80-1,00), Alto (0,60 0,79), Moderado $(0,40-0,59)$, Bajo $(0,20-0,39)$ y Muy Bajo $(0,00-0,19)$. La comparación se analiza en la misma escala, bajo el supuesto que el nivel de especialización más alto lo tendría la región con la base industrial más diversificada y que al interior tenga más sectores especializados. 


\section{ESTRUCTURA DEL COMERCIO INTERNO Y LA PRODUCCIÓN INDUSTRIAL EN COLOMBIA}

\subsection{Especialización y concentración de la producción industrial}

Según los resultados del índice de GINI en términos absolutos, el nivel del especialización de la producción industrial en Colombia es fundamentalmente Moderado (42 \% de los departamentos) y la especialización relativa es Muy baja (52 \% de los departamentos). Los departamentos más especializados, o sea, los que aglomeran gran parte de los ocupados en el interior de sus propias ramas industriales, así como el valor agregado del mismo departamento (especialización absoluta), son: Santander, Boyacá, Bolívar, Tolima, Córdoba, Quindío, Valle, Norte de Santander, Antioquia, Cundinamarca, Bogotá, Risaralda y Atlántico.

En algunos casos como Córdoba, Quindío y Tolima, se nota un nivel de especialización absoluta alto, debido a que son lugares con poca actividad industrial que concentran la producción y el empleo en pocas empresas; sin embargo, estos Departamentos, en términos relativos, están pocos diversificados y tienen un nivel de especialización potencial muy bajo. Si bien departamentos como Bolívar y Boyacá tienen una base industrial algo diversificada, no tienen patrones de especialización relativos muy notables como sí sucede con Santander y Risaralda, que además de tener una base industrial muy amplia, cuentan con varios sub-sectores especializados. En la siguiente tabla se muestra la relación de ambos indicadores. Más detalles de estas clasificaciones y los resultados de cada índice de especialización se presentan en el anexo A.

Tabla 4. Colombia. Especialización del VAM y la ocupación industrial (2008-2009)

\begin{tabular}{|c|c|c|c|c|c|c|}
\hline \multirow{2}{*}{$\begin{array}{c}\text { Grado } \\
\text { de especialización }\end{array}$} & \multicolumn{3}{|c|}{ Especialización absoluta } & \multicolumn{3}{|c|}{ Especialización relaqtiva } \\
\hline & VAM & Ocupados & Promedio & VAM & Ocupados & Promedio \\
\hline Muy alto & $8 \%$ & $0 \%$ & $0 \%$ & $8 \%$ & $12 \%$ & $8 \%$ \\
\hline Alto & $52 \%$ & $12 \%$ & $36 \%$ & $12 \%$ & $4 \%$ & $8 \%$ \\
\hline Moderado & $20 \%$ & $60 \%$ & $44 \%$ & $8 \%$ & $16 \%$ & $16 \%$ \\
\hline Bajo & $4 \%$ & $16 \%$ & $8 \%$ & $32 \%$ & $16 \%$ & $16 \%$ \\
\hline Muy bajo & $16 \%$ & $12 \%$ & $12 \%$ & $40 \%$ & $52 \%$ & $52 \%$ \\
\hline Total & $100 \%$ & $100 \%$ & $100 \%$ & $100 \%$ & $100 \%$ & $100 \%$ \\
\hline
\end{tabular}

Fuente: elaboración propia con base en DANE. EAM

Si se analiza el grado de especialización de acuerdo con el valor agregado de la industria, se nota que Santander, ocupa el primer lugar en la especialización abso- 
luta por cuenta del sector de alimentos y bebidas $[15]^{6}$ y la fabricación de calzado y marroquinería [19]; sin embargo, en términos de especialización relativa está en el tercer puesto después de Bogotá, Antioquia y Valle, de esto modo, esta última clasificación es más coherente con la realidad del país. Los departamentos del Tolima y Norte de Santander, aunque no son muy especializados por concentración de ocupados, tienen una aglomeración muy importante del valor agregado y la producción bruta, especialmente en la industria de alimentos y bebidas [15] y para el último en la fabricación de muebles [36]; sin embargo, el nivel de especialización relativa de estos departamentos es bajo.

La especialización relativa (gráfico derecha) plantea que Bogotá, Antioquia, Valle, Santander, Cundinamarca y Atlántico son departamentos que tienen una base industrial muy amplia de acuerdo con el total de la industria del país; sin embargo, solo los tres primeros tienen un nivel de especialización relativa mayor frente al resto de regiones. En el análisis de la especialización absoluta (gráfico izquierda), se nota que existen departamentos con sectores que concentran de manera considerable el valor agregado y el empleo al nivel interno como son Boyacá, Tolima, Bolívar, Quindío y Córdoba; pero en comparación con otras regiones tienen un potencial productivo poco diversificado y poco especializado en sus propios sectores.

Gráfico 1. Especialización absoluta y relativa por departamento (2008-2009)

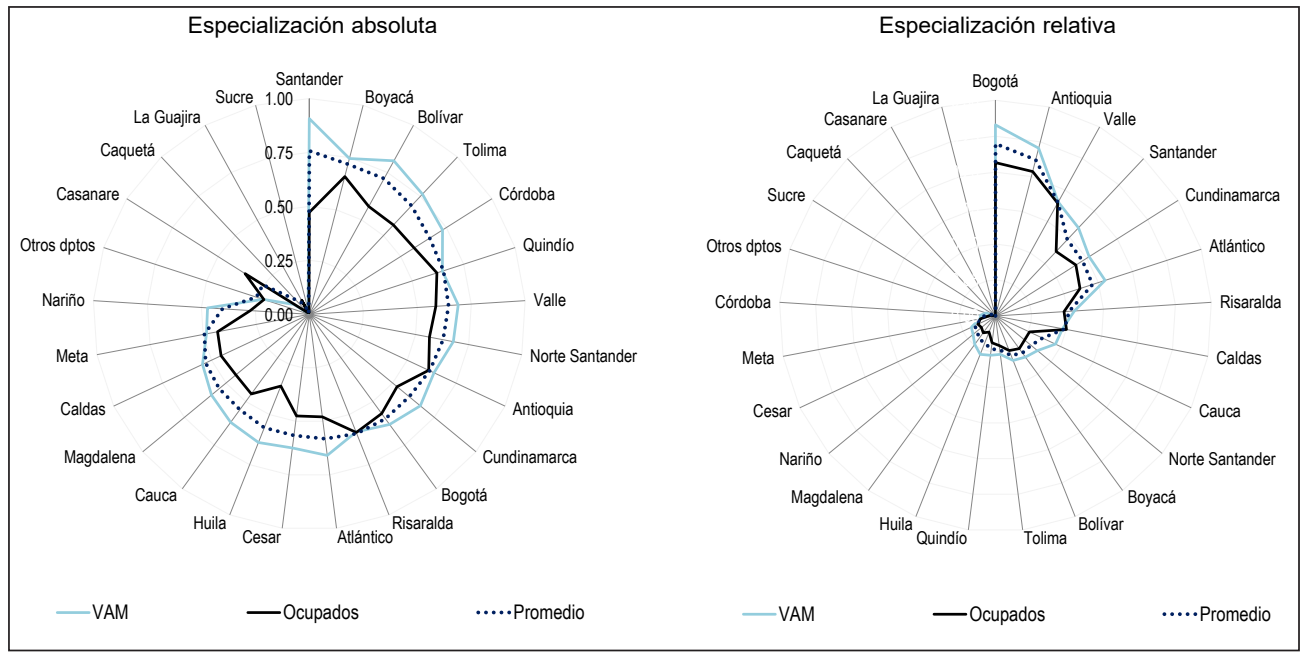

Fuente: elaboración propia con base en DANE. EAM

\footnotetext{
${ }^{6}$ Los valores entre corchete hacen referencia al código CIIU de la gráfica 2, los cuales se presentan detallados en la tabla 7 del anexo C.
} 
Gráfico 2. Concentración absoluta y relativa por rama de actividad (2008-2009)7

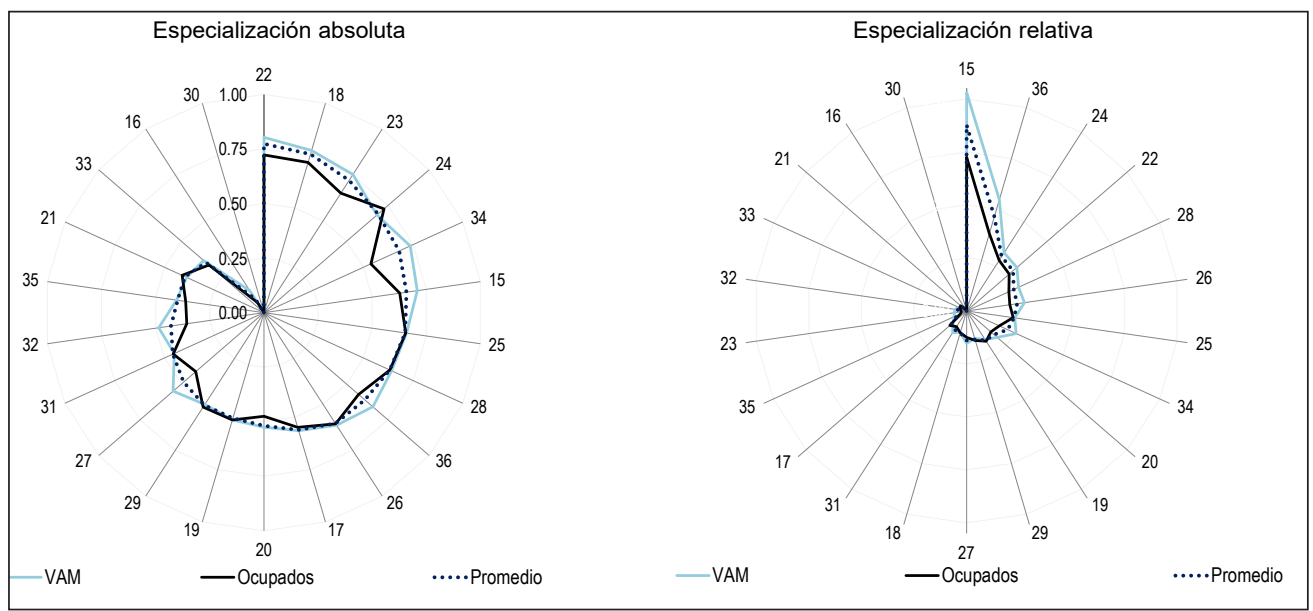

Fuente: elaboración propia con base en DANE. EAM

Para el caso de las ramas de actividad se tuvo en cuenta el grado de concentración que analiza de qué manera está distribuida la producción de una determinada industria entre las distintas regiones colombianas. Los resultados de la concentración absoluta indican que sectores como edición, impresión y reproducción de grabaciones [22]; la industria textil y artículos de piel [18]; actividades de coquización y fabricación de productos derivados de la refinación de petróleo [23]; sustancias y productos químicos [24] y la industria automotriz [34] son los que están más concentrados en pocas regiones del país, bien sea por características geográficas del producto o por el mayor nivel tecnológico, particular de las regiones más especializadas.

Para el caso de la rama de edición, impresión y reproducción de grabaciones [22], está concentrada en los departamentos del Valle, Atlántico, Bogotá, Cauca y Antioquia, mientras que en la industria textil y artículos de piel la producción es particular del Norte de Santander.

En las actividades de coquización y fabricación de productos derivados de la refinación de petróleo [23], Atlántico es el que concentra la mayor parte de la industria frente al resto de departamentos, aunque el nivel de especialización productiva es relativamente bajo. Del mismo modo, la industria automotriz [34] está moderadamente concentrada en Antioquia, Bogotá y Risaralda. Y para el caso de la fabricación de alimentos y bebidas [15], la producción es más alta en departamentos como Tolima, Cundinamarca, Huila y Magdalena.

\footnotetext{
${ }^{7}$ Los números hacen referencia al código CIIU a dos dígitos para cada sector, los cuales se presentan detallados en el anexo C.
} 
El análisis de concentración relativo es primordialmente importante para sectores como alimentos y bebidas [15], y la fabricación de muebles [36] y minerales no metálicos [26], ya que para todos se notó alguna dinámica productiva en casi todas las regiones del país; sin embargo, solo alimentos [15] tiene unos niveles de concentración geográfica mayor, acompañados de unos niveles especialización del sector, en particular para las regiones ya mencionadas. Este resultado contrasta con lo expuesto por Jaramillo y Parra (2012) donde se menciona que el sector es el más dinámico en todo el país, ya que casi todas las regiones producen alimentos.

\subsection{Flujos de comercio interno}

De acuerdo con la teoría contemporánea, el comercio debería de ser más dinámico entre las regiones especializadas que concentran la producción en bienes transables con otras regiones que también estuvieran especializadas en sectores diferentes o en los mismos sectores, pero con productos diferenciados que respondan a las distintas preferencias de los consumidores. En tal sentido, se analizó la influencia de la especialización productiva y la concentración de la producción sobre el comercio intraindustrial en Colombia.

A partir de información de INVIAS sobre los volúmenes de tránsito promedio diario semanal (TPDS-2010), se determinó que en cada estación de conteo se registran aproximadamente 3.859 vehículos en un día promedio/semana ${ }^{8}$ de los cuales se estima que el 30 \% son vehículos de carga. Los departamentos más concurridos son Cundinamarca, Risaralda, Valle, Tolima, Antioquia, Córdoba, Atlántico, los Santanderes, Magdalena y Quindío.

Los resultados de la encuesta de Origen-Destino de carga terrestre del Ministerio de Transporte dan cuenta de que el mayor generador de viajes cargados en Colombia es el departamento del Valle, al tiempo que Bogotá y Antioquia son los mayores receptores. Estos resultados ratifican los hallazgos de Pérez (2005) sobre las regiones protagonistas del movimiento de carga, que hacen parte de los colosales nodos de producción y son las que albergan grandes centros de consumo, en lo que se denomina el triángulo de oro en el interior del país, formado por Bogotá, Cali y Medellín. Según Jaramillo y Parra (2012, p. 82), esto es el resultado del patrón de especialización industrial que provocó el modelo de sustitución de importaciones y promoción de exportaciones de la década de los sesenta y que hace que hoy en día la economía colombiana se organice en una especia de "... modelo cuadricefálico en el que las principales ciudades del país, concentraron el grueso de la producción industrial y la mayor diversificación de la oferta".

\footnotetext{
${ }^{8}$ Se tomó como medida de tendencia central la mediana ya que los datos están muy dispersos en vista que Cundinamarca concentra la mayoría del volumen de tránsito. Media=5.167 y Des. Standard=2.641.
} 
Asimismo, Bolívar, Atlántico y los Santanderes tienen una participación importante como departamentos generadores y receptores de carga, en vista de que soportan el flujo derivado del comercio exterior a través del Caribe y Venezuela. Para el caso del Valle, se reconoce la dinámica de Buenaventura como receptor de carga ya que aproximadamente el 19,8 \% de los viajes del departamento van con destino al puerto. De igual manera este lugar genera el 23 \% de la carga proveniente del Valle hacia el resto del país. En el siguiente gráfico se presenta la relación de regiones generadoras y receptoras de carga terrestre en Colombia.

\section{Gráfico 3. Regiones generadoras y receptoras de carga terrestre}

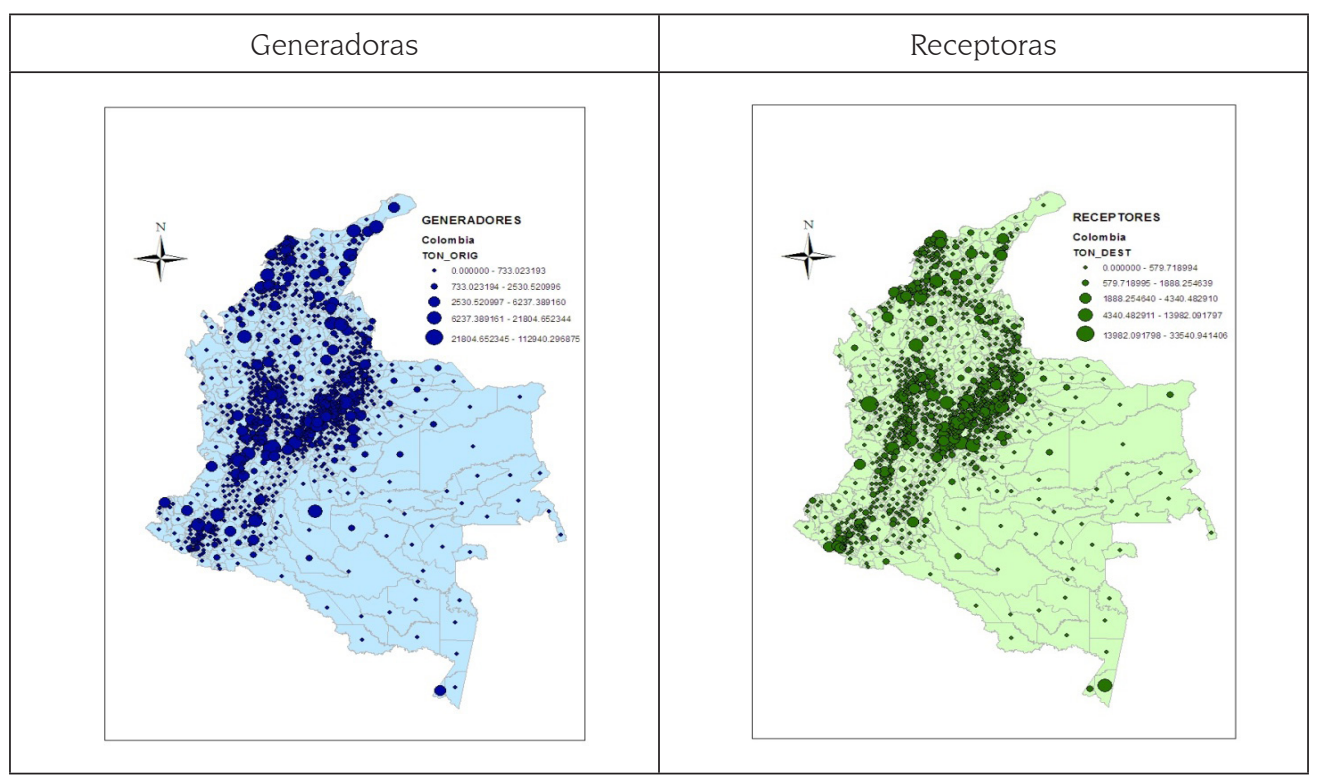

Fuente: elaboración propia a partir de Ministerio del Transporte. Matrices 0-D de 2008.

En promedio el 87,2 \% de la carga movilizada en el interior del país se concentra en productos manufacturados, especialmente de la industria de alimentos y bebidas [15], mercancías en general [98] y sustancias y productos químicos [24]; estos tres suman más de la mitad de la carga de bienes industriales. El sector primario participa únicamente con el 1,4 \%, concentrado básicamente en el transporte de madera y animales. Entre tanto, los productos del sector minero tienen una participación del $11,3 \%$, destacándose la carga de cemento y cales, productos minerales de hierro y minerales para la fabricación de abonos.

En el gráfico 4 se muestran los principales productos movilizados por carretera, que suman más del 60 \% de la carga terrestre registrada en la encuesta de origen- 
destino del Ministerio de Transporte. Cabe aclarar que los resultados pueden tener un sesgo muy importante debido a la recolección no probabilística de los datos y, además, para el caso de este trabajo, la ausencia de observaciones de años anteriores. No obstante, según Pérez (2005), el carbón, los productos químicos, básicos, al igual que el maíz, el cemento, el azúcar y el papel tuvieron una participación importante en la carga movilizada en el año 2001, lo que es consistente con los productos más dinámicos en 2008. En el anexo B se presentan las estadísticas del volumen de carga y el número de viajes según el tipo de productos.

\section{Gráfico 4. Porcentaje de carga movilizada por carretera}

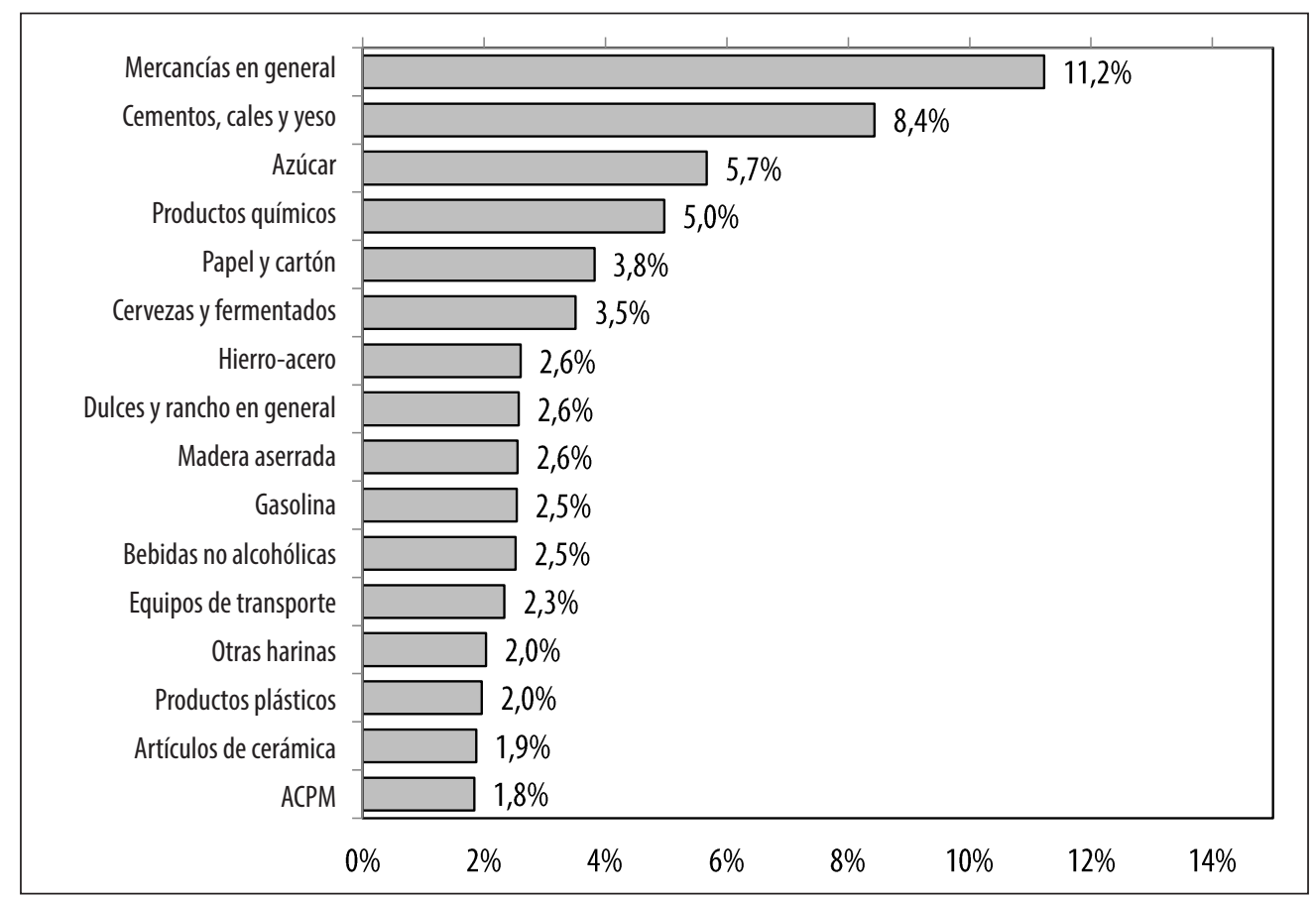

Fuente: elaboración propia a partir de Ministerio del Transporte. Matrices 0-D de 2008

Aparentemente, la especialización productiva no explica del todo los flujos de comercio en el interior del país para algunos productos, ya que hay sectores muy concentrados en ciertas regiones, que no tienen un patrón de carga movilizada muy significativo. Este resultado, de acuerdo con Castro (2014), podría está ligado a la naturaleza transable del bien manufacturado y seguramente al nivel de demanda local. Por ejemplo, la industria de fabricación de muebles [36], caucho y plástico [25], curtido y adobo cueros [19], productos derivados metal [28], industria automotriz [34] y la industria de edición e impresión [22], aunque tienen un nivel de especialización 
importante en varias regiones, parece que no son altamente sustituibles por los de otros departamentos, no hay suficientes incentivos para comercializarlos en grandes magnitudes o simplemente son acaparados por la demanda local. Este caso resultó ser particular en la fabricación de muebles [36] ya que tienen una dinámica importante en casi todas las regiones y en ellas hay presencia de sectores muy especializados, lo que probablemente explica la poca movilización de carga por ser un mercado de autoabastecimiento.

No obstante, en otros sectores la especialización sí viene acompañada de alta movilidad de productos; este el caso de la industria de alimentos y bebidas [15], sustancias y productos químicos [24] y minerales no metálicos [26] que tienen una base industrial diversificada cuando se analizan por sectores (ciiu 2d) y, a la vez, muy especializada en algunas sub-ramas (ciiu 3d). Otros productos como los derivados de la industria textil [18], maquinaria y equipos [29], aparatos eléctricos [31], tabaco [16], instrumentos médicos [33], equipos de transporte [35] y maquinaria de oficina [30] tienen un nivel de especialización moderado que, a su vez, se corresponde con el bajo flujo de carga registrado. En este grupo de productos, la especialización relativa resulta más importante para determinar el comercio.

Finalmente, los productos metalúrgicos básicos [27] y la industria de papel y cartón [21] tienen un nivel de comercialización regional considerable, pese a que no existe un nivel de especialización muy importante y la concentración geográfica es moderada y baja. Por su parte, los productos derivados de la refinación de petróleo y coquización [23] también tienen un flujo de carga destacado, a pesar que los productores no están muy especializados. Este hecho puede explicarse por la alta concentración regional de la producción en pocos departamentos y probablemente las necesidades de insumos que se extienden por todo el territorio nacional, independiente del nivel de especialización de los proveedores (por ejemplo la madera o los subproducto del metal como chatarras). Para los casos anteriores la especialización absoluta es más favorable para entender el comercio regional.

Los resultados anteriores plantean que no en todos los sectores industriales la especialización es determinante del comercio; hay casos en que una industria puede estar altamente especializada y no tener flujos comerciales importantes, como también puede suceder que los movimientos de carga sean considerables, pese a que el sector no esté concentrado o que las regiones productoras no estén especializadas. Se estima que este hecho está asociado a la naturaleza transable del producto y al nivel de demanda local de las regiones productoras. En la gráfica 5 se muestra una clasificación más clara: 
Gráfico 5. Relación entre comercio y especialización industrial

\begin{tabular}{|c|c|}
\hline INDUSTRIA DE AUTOCONSUMO & INDUSTRIA DIVERSIFICADA Y \\
\hline Fabricación de muebles & MUY ESPECIALIZADA \\
\hline Caucho y plástico [25] & Alimentos y bebidas [15] \\
\hline Curtido y adobo cueros [19] & Sustancias y productos químicos \\
\hline Productos derivados metal & Minerales no metálicos [26] \\
\hline Industria automotriz [34] & \\
\hline Edición e impresión [22] & \\
\hline INDUSTRIA ESPECÍFICA & INDUSTRIA GLOBAL NO \\
\hline Maquinaria y equipos npc & ESPECIALIZADA \\
\hline Industria textil [18] & Metalúrgicos básicos [27] \\
\hline Aparatos eléctricos [31] & Papel y cartón [21] \\
\hline Tabaco [16] & Petróleo y coquización [23] \\
\hline Instrumentos médicos [33] & \\
\hline Equipos de transporte [35] & \\
\hline Maquinaria de oficina [30] & \\
\hline
\end{tabular}

Fuente: elaboración propia

Se nota con particularidad que los departamentos con una base industrial más diversificada y que en su interior tenga sub-ramas especializadas tienden a presentar una mayor dinámica comercial con otras regiones con características similares. En ese sentido, se podría pensar que los flujos del comercio interno se explican mejor por la diversificación de la base industrial acompañada de muchos sub-sectores especializados en lugar de la especialización absoluta en pocos sectores, es decir, no basta tener especialización absoluta ya que la dinámica del comercio se fundamenta básicamente en la mayor diversificación de la oferta especializada lo que es consistente con las propuestas de Krugman (1980) sobre la dinámica del comercio.

\section{CONCLUSIONES}

La estrategia de integración regional para la diversificación y fortalecimiento del comercio industrial en Colombia debería estar orientada hacia la promoción de inversiones en sectores industriales con mayor base tecnológica, mayor potencial para generar encadenamientos productivos y necesariamente actividades clave que registren una buena dinámica de movimiento de carga y mercancías entre los potenciales socios comerciales. 
Los resultados empíricos permiten pensar que los flujos del comercio interno en Colombia se explican mejor por la diversificación de la base industrial acompañada de muchos sub-sectores especializados, en lugar de la especialización absoluta en unos pocos, ya que la dinámica del comercio se fundamenta básicamente en la variedad de oferta especializada. Este resultado es consistente con los planteamientos de Dixit y Stiglizt (1977) sobre la teoría de la diferenciación del producto que considera las diferencias en las preferencias de los consumidores bajo el argumento de que estos desearían obtener el mayor número de variedades de un bien diferenciado por atributos y características particulares, lo que daría mayor dinamismo al comercio. Este hecho es más evidente en la comercialización de productos manufacturados de la industria de alimentos y bebidas [15] donde el nivel de especialización productiva en varias regiones viene acompañado, además, por importantes flujos comerciales.

Sin embargo, este fenómeno no se explica de la misma forma para algunos productos, ya que hay sectores que pueden tener un nivel de especialización regional muy parecido y no presentan patrones de carga movilizada muy significativos entre sí. Los resultados pueden estar asociados a la naturaleza transable del bien manufacturado y seguramente al nivel de demanda local, ya que ciertos productos parece que son poco sustituibles por los de otras regiones, no hay suficientes incentivos para comercializarlos en grandes magnitudes o simplemente son acaparados por la demanda local. El caso resultó particular de la industria de muebles [36] que es un mercado de autoabastecimiento.

Los indicadores de especialización productiva muestran que Bogotá, Antioquia, Valle, Santander, Cundinamarca y Atlántico son departamentos que tienen una base industrial muy amplia de acuerdo con el total de la industria del país. En promedio el $87,2 \%$ de la carga movilizada en el interior se concentra en productos manufacturados, especialmente de la industria de alimentos y bebidas [15], mercancías en general [98], y sustancias y productos químicos [24]; estos tres suman más de la mitad de la carga de bienes industriales.

En este documento se presenta un panorama general de los sectores y las regiones más dinámicas frente a la generación y recepción de carga terrestre en Colombia, con el ánimo de identificar características de los principales protagonistas del comercio interno en Colombia que puedan favorecer las relaciones comerciales de la industria local. De este modo, no se presentan líneas estratégicas sobre políticas regionales de desarrollo del sector manufacturero o recomendaciones de integración regional, en vista de que se debe considerar una mirada más holística sobre las condiciones de transporte de carga en el país, la infraestructura, las posibilidades de encadenamientos por redes empresariales y el aprovechamiento de las condi- 
ciones de competitividad sectorial. No obstante, el ejercicio deja la puerta abierta a futuros trabajos de investigación que intenten hacer validaciones econométricas sobre la relación de la especialización productiva como determinante de los flujos comerciales en los ámbitos sectorial y regional, que incluyan estas variables mediante el uso de métodos gravitacionales.

\section{BIBLIOGRAFÍA}

Álvarez, Dorotea de Diego (2005). Un análisis de la variación del comercio intra-industrial en España (1988-1999): medida y costes de ajuste. Tesis Doctoral, Facultad de Ciencias Económicas y Empresariales, Departamento de Economía Aplicada II (Estructura Económica y Economía Industrial), Universidad Complutense de Madrid, 289p.

Álvarez, Dorotea de Diego y Troyano, Miguel (2006). Comercio intra-industrial en España (19881999) un análisis con variables dummies. En: Revista del CES Felipe II, No. 5, 18p.

Appleyard, Dennis R. y Field Alfred J. (2003). Economía Internacional. Madrid, Editorial McGraw-Hill, Cuarta Edición, 360p.

Bajo, Oscar (1991). Teorías del comercio internacional. Barcelona, Editorial Antoni Bosch, 160p.

Berumen, Sergio (2006). Introducción a la economía internacional. Madrid, Editorial ESIC, 410p.

Bonet, Jaime (1999). El crecimiento regional en Colombia, 1980-1996: una aproximación con el método Shift-Share. En: Documentos de Trabajo sobre Economía Regional, Centro de estudios Económicos Regionales, Banco de la República. No. 10, p. 50.

Bonet (2005) Cambio estructural regional en Colombia: una aproximación con matrices insumo-producto. En: Documentos de Trabajo sobre Economía Regional. Centro de Estudios Económicos Regionales, Banco de la República. No. 62, 59p.

Bosco, M. (2005). Patterns of specialization and concentration in a polarized country: the case of italian regions. En: ISLA Working Papers, No. 22, Istituto di Studi Latino- Americani e dei Paesi in transizione (ISLA), Università Commerciale "Luigi Bocconi", Milano, Italy, 25p.

Burbano, E. (2015). Reestructuración sectorial en el putumayo: una dinámica de "tres velocidades". En: Revista Investigación y Reflexión. Universidad Militar Nueva Granada, Vol. 23, No. 2, p. $\overline{115}-139$.

Castro, Edisson (2014). Relaciones comerciales de la producción industrial en el mercado interno colombiano, En: Revista Ecos de Economía, Universidad EAFIT. Vol. 18, No. 39, p. 73-95.

Dixit, Avinash y Stiglitz Josep (1977). Monopilistic competition and optimum product diversity. En: American Economic Review, Vol. 67, No. 3, junio, p. 297-308.

Emaldi, Iñaki Aitor (1991). Un análisis empírico de los determinantes de la especialización productiva y comercial de Euskadi. En: Ekonomiaz: Revista vasca de economía, No. 21, p. 210-226.

Furió, E. y Alonso, M. (2008). Concentración económica, Algunas consideraciones sobre su naturaleza y medida. En: Boletín Económico de ICE, No. 2947, Información Comercial Española, p. 41-54. 
Gordo, Esther; Gil, María y Pérez, Miguel (2003). Los efectos de la integración económica sobre la especialización y distribución geográfica de la actividad industrial en los países de la UE. Documentos ocasionales, Banco de España, Working paper, No. 0303, 63p.

Jaramillo, J. y Parra, J. (2012). Evolución de la concentración y especialización industrial en Colombia, 1975-2005. En: Ensayos de Economía, Universidad Nacional de Colombia, Sede Medellín, Vol. 22, No. $\overline{40}$, p. 81-102.

Jaumandreu, J. y Mato, G. (1985). Concentración industrial en España. 1973-1981. En: Fundación Empresa Pública, Documento de trabajo No. 8504, p. 45-56.

Krugman, Paul (1980). Scale Economies, Product Differentiation, and the Pattern of Trade, En: American Economic Review, Vol. 70, No. 5, p. 950-959.

Krugman, Paul (1991). Increasing Returns and Economic Geography, En: Journal of Political Economy, Vol. 99, No. 3, p. 483-499.

Krugman, Paul (1992). Geografía y Comercio. Barcelona, Antoni Bosch, 152p.

Krugman, Paul (1998). The Role of Geography on development, En: Annual World Bank Conference on Development Economics, Washington D.C., Edited by B. Pleskovic and J. Stiglitz, 4lp.

Martin, Joan y Orts, Vicente (1996). Naturaleza y causas del comercio intra-industrial. En: Ekonomiaz: Revista vasca de economía, No. 36, p. 78-101.

Martin, Joan y Orts, Vicente (2002). Comercio Intra-Industrial español: especialización vertical y ventaja comparativa. En: Revista de Economía Aplicada, Vol. 10, No. 30, p. 25-51.

Melitz, M. (2003). The Impact of Trade on Intraindustry Reallocations and Aggregate Industry Productivity, En: Econometrica, Vol. 71, No. 6, p. 1695-1725.

Melitz, M. J. y Ottaviano, G. I. P. (2008). Market Size, Trade, and Productivity, En: Review of Economic Studies, Vol. 75, No. 1, p. 295-316.

Pérez, Gerson (2005). La infraestructura del transporte vial y la movilización de carga en Colombia. En: Documentos de trabajo sobre economía regional. Banco de la República, No. 64, 67p.

Rapún, M.; Ezcurra, R.; Gil, C. y Pascual, P. (2003). Distribución espacial de la actividad económica: especialización y desigualdad en las regiones de la Unión Europea. Departamento de Economía, Universidad Pública de Navarra, 59p.

Tipurić, D., Pejić, M., (2009). Changes in industrial concentration in the croatian economy (19952006). En: EFZG Working Papers Series 0903, Faculty of Economics and Business, University of Zagreb, 35p.

White, Lawrence J. (1974). Industrial organization and international trade: some theoretical considerations. En: American Economic Review, Vol. 64, No. 6, p. 1013-1020. 


\section{ANEXOS}

ANEXO A.

Colombia. Indicadores de especialización industrial (2008-2009)

\begin{tabular}{|c|c|c|}
\hline Departamentos & Especialización Absoluta & Especialización Relativa \\
\hline Antioquia & 0,62 & 0,22 \\
\hline Atlántico & 0,58 & 0,14 \\
\hline Bogotá & 0,60 & 0,24 \\
\hline Bolívar & 0,72 & 0,06 \\
\hline Boyacá & 0,72 & 0,06 \\
\hline Caldas & 0,53 & 0,10 \\
\hline Caquetá & 0,09 & 0,00 \\
\hline Casanare & 0,25 & 0,00 \\
\hline Cauca & 0,55 & 0,07 \\
\hline Cesar & 0,57 & 0,03 \\
\hline Córdoba & 0,66 & 0,01 \\
\hline Cundinamarca & 0,60 & 0,14 \\
\hline Huila & 0,57 & 0,04 \\
\hline La Guajira & 0,06 & 0,00 \\
\hline Magdalena & 0,54 & 0,04 \\
\hline Meta & 0,49 & 0,02 \\
\hline Nariño & 0,40 & 0,03 \\
\hline Norte Santander & 0,63 & 0,06 \\
\hline Quindío & 0,65 & 0,05 \\
\hline Risaralda & 0,60 & 0,10 \\
\hline Santander & 0,76 & 0,15 \\
\hline Sucre & 0,01 & 0,00 \\
\hline Tolima & 0,69 & 0,05 \\
\hline Valle & 0,64 & 0,18 \\
\hline Otros departamentos & 0,26 & 0,01 \\
\hline
\end{tabular}

Fuente: elaboración propia con base en DANE. EAM 


\section{ANEXO B.}

\section{Proporción de carga movilizada por carretera (2008).}

\begin{tabular}{|c|c|c|c|c|c|}
\hline Actividad & Sector & $\begin{array}{l}\text { Miles de } \\
\text { toneladas }\end{array}$ & $\%$ & $\begin{array}{c}\text { Miles de } \\
\text { Viajes }\end{array}$ & $\%$ \\
\hline \multirow{2}{*}{$\begin{array}{l}\text { Agricultura, } \\
\text { Ganadería }\end{array}$} & Silvicultura, madera y act. de servicios conexas & 0,96 & $75,2 \%$ & 0,63 & $66,4 \%$ \\
\hline & Agricultura, ganadería y caza & 0,32 & $24,8 \%$ & 0,32 & $33,6 \%$ \\
\hline \multicolumn{2}{|l|}{ SUBTOTAL } & 1,28 & $1,3 \%$ & 0,94 & $1,6 \%$ \\
\hline \multirow{23}{*}{$\begin{array}{l}\text { Industrias Ma- } \\
\text { nufactureras }\end{array}$} & Productos alimenticios y bebidas & 24,87 & $29,9 \%$ & 14,31 & $27,0 \%$ \\
\hline & Mercancías general & 10,93 & $13,1 \%$ & 7,32 & $13,8 \%$ \\
\hline & Sustancias y productos químicos & 7,41 & $8,9 \%$ & 3,78 & $7,1 \%$ \\
\hline & Otros productos minerales no metálicos & 5,95 & $7,1 \%$ & 3,45 & $6,5 \%$ \\
\hline & Productos metalúrgicos básicos & 5,70 & $6,8 \%$ & 2,84 & $5,4 \%$ \\
\hline & Productos derivados de la refinación de petróleo & 5,36 & $6,4 \%$ & 2,54 & $4,8 \%$ \\
\hline & Vehículos automotores, remolques y semirremolques & 4,02 & $4,8 \%$ & 3,68 & $6,9 \%$ \\
\hline & Papel, cartón, productos de papel y cartón & 3,89 & $4,7 \%$ & 2,69 & $5,1 \%$ \\
\hline & Muebles, industrias manufactureras ncp & 3,56 & $4,3 \%$ & 3,30 & $6,2 \%$ \\
\hline & Productos de caucho y de plástico & 3,55 & $4,3 \%$ & 2,95 & $5,6 \%$ \\
\hline & Maquinaria y equipo NCP & 2,77 & $3,3 \%$ & 2,43 & $4,6 \%$ \\
\hline & Productos de madera y corcho (excepto muebles) & 2,71 & $3,3 \%$ & 1,67 & $3,2 \%$ \\
\hline & Fabricación de productos textiles & 0,91 & $1,1 \%$ & 0,71 & $1,3 \%$ \\
\hline & Maquinaria y aparatos eléctricos ncp & 0,74 & $0,9 \%$ & 0,58 & $1,1 \%$ \\
\hline & Reciclaje & 0,30 & $0,4 \%$ & 0,19 & $0,4 \%$ \\
\hline & Curtido y adobo de cueros (productos de cuero) & 0,27 & $0,3 \%$ & 0,19 & $0,4 \%$ \\
\hline & Maquinaria de oficina, contabilidad e informática & 0,14 & $0,2 \%$ & 0,11 & $0,2 \%$ \\
\hline & Otros tipos de equipos de transporte & 0,05 & $0,1 \%$ & 0,06 & $0,1 \%$ \\
\hline & Productos de tabaco & 0,05 & $0,1 \%$ & 0,06 & $0,1 \%$ \\
\hline & Equipo y aparatos de radio televisión y comunicaciones & 0,04 & $0,0 \%$ & 0,06 & $0,1 \%$ \\
\hline & $\begin{array}{l}\text { Productos elaborados de metal (excepto maquinaria y } \\
\text { equipo) }\end{array}$ & 0,04 & $0,0 \%$ & 0,04 & $0,1 \%$ \\
\hline & Instrumentos médicos, ópticos y de precisión & 0,03 & $0,0 \%$ & 0,03 & $0,1 \%$ \\
\hline & Productos de edición e impresión & 0,01 & $0,0 \%$ & 0,02 & $0,0 \%$ \\
\hline \multicolumn{2}{|l|}{ SUBTOTAL } & 83,30 & $85,5 \%$ & 52,99 & $88,9 \%$ \\
\hline \multirow{2}{*}{$\begin{array}{l}\text { Minas y } \\
\text { canteras }\end{array}$} & Explotación de minerales No Metálicos & 10,28 & $80,2 \%$ & 4,48 & $78,8 \%$ \\
\hline & Extracción de minerales metalíferos & 2,53 & $19,8 \%$ & 1,21 & $21,2 \%$ \\
\hline \multicolumn{2}{|l|}{ SUBTOTAL } & 12,81 & $13,2 \%$ & 5,69 & $9,5 \%$ \\
\hline \multicolumn{2}{|l|}{ TOTAL } & 97,38 & $100,0 \%$ & 59,62 & $100,0 \%$ \\
\hline
\end{tabular}

Fuente: Elaboración propia a partir de MINTRANSPORTE. Matrices 0-D (2008). 


\section{ANEXO C.}

\section{Clasificación CIIU a dos dígitos por ramas de actividad}

\begin{tabular}{|c|l|}
\hline CIU & RAMA \\
15 & Elaboración de productos alimenticios y bebidas \\
16 & Fabricación de productos de tabaco \\
17 & Fabricación de productos textiles \\
18 & Confección de prendas de vestir, adobo y teñido de pieles \\
19 & Curtido y adobo de cueros, fabricación de zapatos, fabricación de artículos de viaje, \\
20 & maletas... \\
21 & Transformación de madera, fabricación de productos de madera y corcho, excepto mue \\
22 & Fabricación de papel, cartón, productos de papel y cartón \\
23 & Actividades de edición e impresión y de reproducción de grabaciones \\
24 & Fabuización, fabricación de productos de la refinación de petróleo y combustible nuclear \\
25 & Fabricación de productancias y productos químicos \\
26 & Fabricación de otros productos minerales no metálicos \\
27 & Fabricación de productos metalúrgicos básicos \\
28 & Fabricación de productos elaborados de metal, excepto maquinaria y equipo \\
29 & Fabricación de maquinaria y equipo NCP \\
30 & Fabricación de maquinaria de oficina, contabilidad e informática \\
31 & Fabricación de maquinaria y aparatos eléctricos NCP \\
32 & Fabricación de equipo y aparatos de radio televisión y comunicaciones \\
33 & Fabricación de instrumentos médicos, ópticos y de precisión y fabricación de relojes \\
34 & Fabricación de vehículos automotores, remolques y semirremolques \\
35 & Fabricación de otros tipos de equipos de transporte \\
36 & Fabricación de muebles, industrias manufactureras ncp \\
\hline
\end{tabular}

\section{Fuente: elaboración con base en DANE}

